\title{
Field Survey on Human Thermal Comfort Reports in Air-Conditioned Offices in Taiwan
}

\author{
Ruey Lung Hwang*,1 and Ming-Jen Cheng ${ }^{2}$ \\ ${ }^{I}$ Department of Occupational Safety and Health, China Medical University, Taichung, Taiwan \\ ${ }^{2}$ Department of Architecture, Feng-Chia University, Taichung, Taiwan
}

\begin{abstract}
Field experiments, conducted in 29 air-conditioned offices, used survey questionnaires and physical measurements to investigate workers' subjective thermal responses and comfort perception. A total of 650 individuals participated in the field study. The thermal neutrality and thermal preference of subjects occurred at $25.6^{\circ} \mathrm{C}$ and $24.1^{\circ} \mathrm{C}$ respectively. Responses from those subjects suggest a comfort temperature range is $23.8-27.5^{\circ} \mathrm{C}$, that shifts to slightly warmer temperatures by about $0.5^{\circ} \mathrm{C}$ as comparing to comfort zone recommended in ASHRAE standard 55. Responses from subjects also indicate that people in Taiwan have a leniency toward the humidity guideline in ASHRAE standard 55, due to acclimate to the humid climate. The findings were compared with the similar studies in hot-humid climate.
\end{abstract}

Keywords: Thermal comfort, air-conditioned offices, field survey.

\section{INTRODUCTION}

Most of the commercial buildings in Taiwan are equipped with mechanical cooling systems. The energy consumption of air conditioning system has become one of the major issues for these buildings. On the other hand, the office is a place where office workers spend ten hours per day on average. As they have limited control over their own environment, a comfortable and healthy environment should be provided for the office workers to remain comfortable during their working hours. Therefore, in all commercial buildings, both thermal comfort and energy conservation are desired.

The habit standards, such as ISO standard 7730 [1] and ASHRAE Standard 55 [2], have been used for the determination of optimum temperatures in buildings. However, many field studies of thermal comfort, especially conducted in hothumid climate, have suggested that design temperatures derived from these standards would require more energy to achieve thermal comfort than was indicated from the survey results. Actually, the latest revised ASHRAE standard 55 (2004) includes the concept of adaptation as an option. Therefore, there is a potential for energy conservation through careful temperature control if the actual optimum temperature was well known.

The objective of this study is to try to analyze the thermal responses and comfort reception of office workers under real working conditions, by carrying out a field survey in office buildings throughout the country, Taiwan. Attempt was also made to assess whether there is a statistic difference between the measured results and the habit standards.

\section{METHODOLOGY}

\section{Outline}

Field experiments using thermal environment measurements with a questionnaire-based survey was conducted in

*Address correspondence to this author at the Department of Occupational Safety and Health, China Medical University, No.91 Hsueh-Shih Road,Taichung, Taiwan; E-mail: hwangrl@mail.cmu.edu.tw
29 office buildings in Taiwan from May to October 2006. Table 1 shows the characteristics of the buildings and numbers of subjects surveyed. As the measurement on physical environment proceeds, the subjects were invited to answer the questionnaire. A total of 650 workers, 298 males and 352 females, participated in this field study. Subject age ranged from 19-65 years (mean age, 34 years). Subject average weight was $61 \mathrm{~kg}$ and average height was $165 \mathrm{~cm}$. The workers usually engaged in typical office work (1.2 met).

\section{Thermal Environment Measurements}

Physical measurements were conducted around the subjects. Environmental parameters relating to body thermal balance, such as air temperature, mean radiant temperature, relative humidity, and air velocity, were measured at $1.0 \mathrm{~m}$ above the floor. Mean radiant temperature was based on the conversion of globe temperature data measured using a $150 \mathrm{~mm}$ diameter globe thermometer. To obtain stable globe temperature, each experiment lasted for about 20 minutes.

\section{Questionnaire Survey}

Subjects were asked to assess environmental conditions in terms of thermal comfort by filling in the questionnaire. The questionnaire, written in Chinese, was based on the survey form in Appendix E of ASHRAE Standard 55. The major section of the questionnaire, following a preface explaining survey goals, investigated subject thermal perception of the indoor microclimate. In this questionnaire section, subjects were asked to judge how they felt about the thermal environment on a typical 7-point ASHRAE sensation scale. Furthermore, subjects were asked to judge the acceptability of and preference for thermal conditions. A direct acceptability question asked subjects to gauge whether the current thermal condition was 'acceptable' or 'unacceptable'. The McIntyre preference scale (Right now I want to be: cooler, warmer or no change) was used to investigate subject preferences. The remaining sections of the questionnaire obtained subject data including gender, age, weight, and height. Metabolic rate and clothing insulation were also estimated from the questionnaire survey. 
Table 1. Summary of Surveyed Buildings

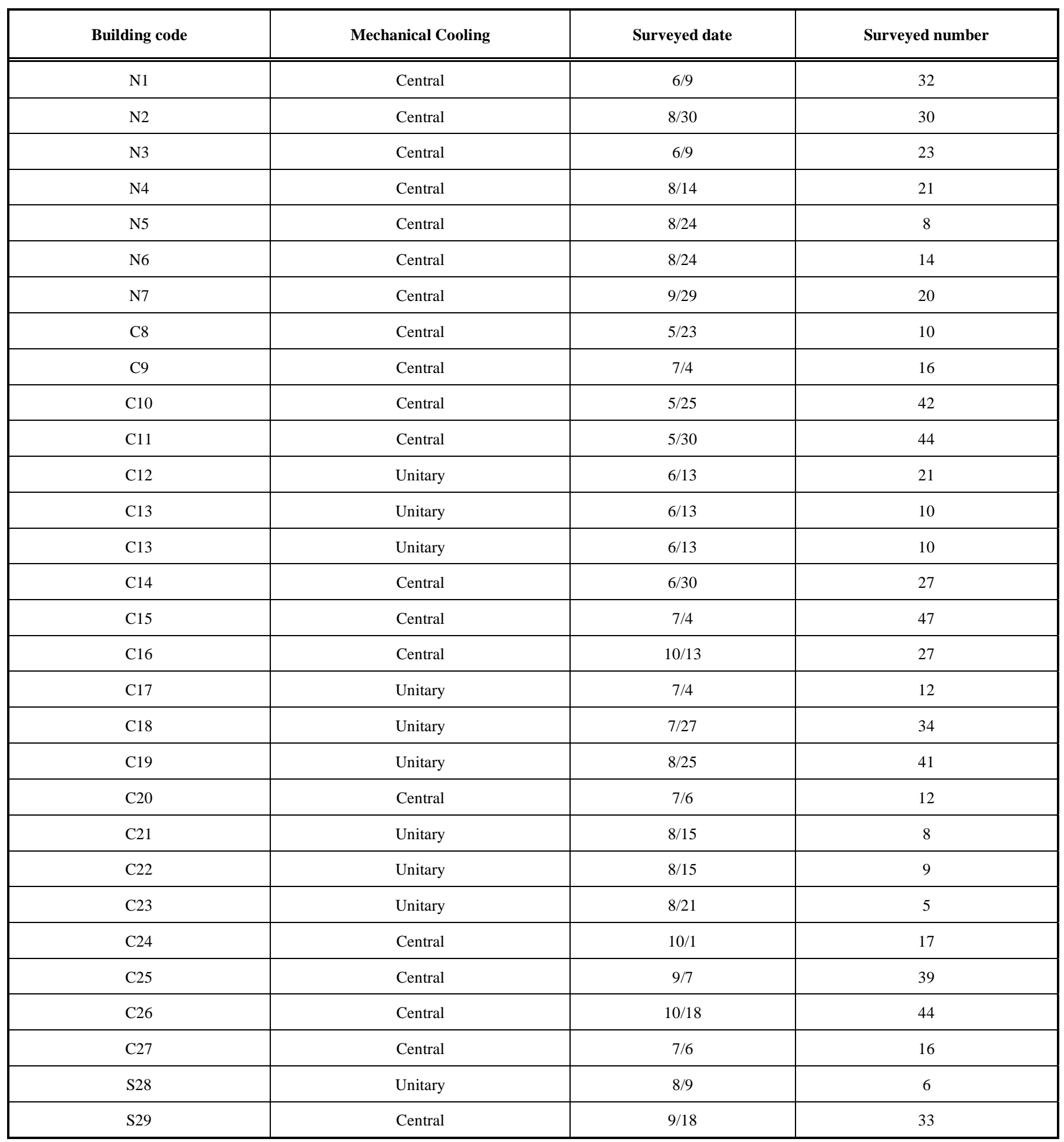

\section{RESULTS AND DISCUSSIONS}

\section{Results of Physical Environment Measurement}

Physical measurements indicate that indoor air temperatures range was $21-32^{\circ} \mathrm{C}$. The distribution of air temperature is in the majority in the range of $24.0-27.0^{\circ} \mathrm{C}$. Values of mean radiant temperature were typically slightly higher than those of air temperature, with differences of $0.2-1.0^{\circ} \mathrm{C}$. The humidity varies from $50 \%$ to $85 \%$. Mean indoor air velocity was $0.19 \mathrm{~m} / \mathrm{s}$, ranging from $0.1-0.5 \mathrm{~m} / \mathrm{s}$. Table 2 lists the frequency of gauged indoor environment parameters (temperature and relative humidity) and the estimated thermal comfort parameters (mean radiant temperature and operative temperature) with statistics binned into $1{ }^{\circ} \mathrm{C}$ intervals.

For detailed observations of measurements, the conditions measured in each experiment were plotted on the ASHRAE psychometric chart of thermal comfort, as shown 
Table 2. Frequency of Environment Parameters

\begin{tabular}{|c|c|c|c|c|c|c|}
\hline Temperature $\left({ }^{\circ} \mathrm{C}\right)$ & 21 & 22 & 23 & 24 & 25 & 26 \\
\hline Dry bulb & $1 \%$ & $3 \%$ & $5 \%$ & $24 \%$ & $15 \%$ & $15 \%$ \\
\hline MRT & $0 \%$ & $0 \%$ & $2 \%$ & $12 \%$ & $15 \%$ & $16 \%$ \\
\hline $\mathrm{T}_{\mathrm{O}}$ & $0 \%$ & $0 \%$ & $5 \%$ & $14 \%$ & $21 \%$ & $14 \%$ \\
\hline $\mathrm{RH}$ & $0 \%$ & $0 \%$ & $2 \%$ & $12 \%$ & $12 \%$ & $36 \%$ \\
\hline
\end{tabular}

\begin{tabular}{|c|c|c|c|c|c|c|}
\hline Temperature $\left({ }^{\circ} \mathrm{C}\right)$ & 27 & 28 & 29 & 30 & 31 & 32 \\
\hline Dry bulb & $24 \%$ & $7 \%$ & $4 \%$ & $2 \%$ & $0 \%$ & $1 \%$ \\
\hline MRT & $16 \%$ & $23 \%$ & $8 \%$ & $4 \%$ & $3 \%$ & $1 \%$ \\
\hline $\mathrm{T}_{\mathrm{O}}$ & $20 \%$ & $16 \%$ & $3 \%$ & $4 \%$ & $1 \%$ & $0 \%$ \\
\hline RH & $22 \%$ & $10 \%$ & $2 \%$ & $4 \%$ & $0 \%$ & $0 \%$ \\
\hline
\end{tabular}

†GT:Global Temperature; MRT: mean radiant temperature.

$\mathrm{T}_{\mathrm{O}}$ : operative temperature; $\mathrm{RH}$ : relative humidity.

in Fig. (1). The comfort zone imposed on this figure is for 0.6 clo of clothing insulation, which is the subjects' mean clothing level during the survey. In all measured data, $31 \%$ of them fell within the comfort zone, $5 \%$ of them fell on the cool side of comfort zone, $40 \%$ of them fell on the hot side of comfort zone, and the rest of them gave humidity fell outside the guideline while temperatures within the recommended prescriptions.

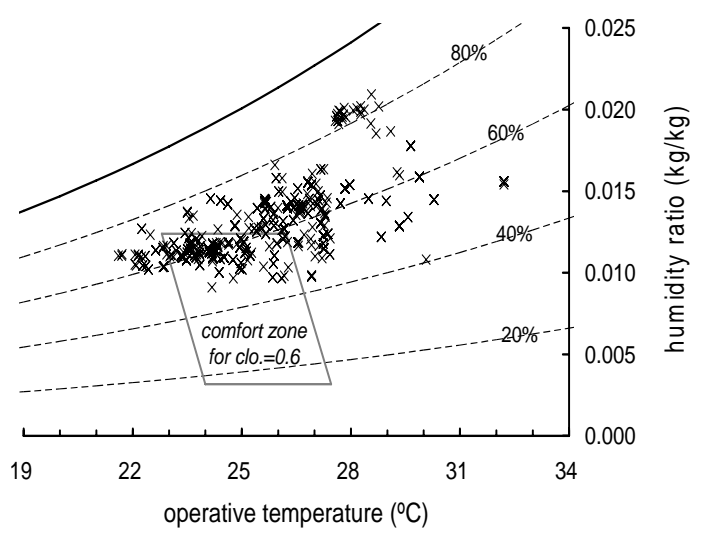

Fig. (1). Distribution of the indoor thermal condition on ASHRAE standard 55 comfort chart.

Since the ASHRAE comfort psychometric chart expresses the comfort temperature in terms of operative temperature, the following discussions is expressed in this unit of temperature. The operative temperature is temperature which calculates the combination effect of air and radiant temperature from the surfaces.

\section{Analysis of Subjects' Thermal Responses}

Fig. (2) presents a comparison of thermal satisfaction assessed using the following three Models: direct acceptability, central 3 categories of TSV and thermal preference votes of "no-change". For thermal acceptability, $88 \%$ of subjects found the thermal environment conditions around them acceptable (satisfied). By equating the central three categories $(-1,0,+1)$ of the ASHRAE scale with an expression of satisfaction, $78 \%$ of subjects were satisfied with thermal conditions. For thermal preference, $54 \%$ of subjects indicated "no change" suggesting that they were satisfied with conditions. In comparison, only $31 \%$ of measured physical conditions fell into the summer comfort zone of ASHRAE standard 55.

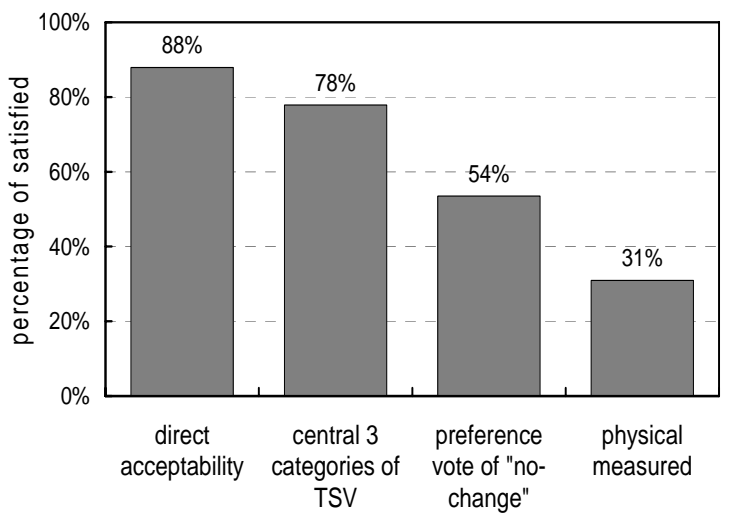

Fig. (2). Comparison of observed percentages of satisfied from various survey methods.

These survey results suggest that subjects have gauged their thermal sensation, preference and acceptability different 
from that of ASHRAE Standard 55 recommended. However, correlations between judgments of thermal sensation and acceptability or preference are discussed first as follows.

Fig. (3) plots the percentages of unacceptability against the 7-point sensation scale for all subjects. By dealing "unacceptability" and "dissatisfaction" as synonyms, the percentage of those unsatisfied with thermal condition can be compared with the predicted percentages of dissatisfied (PPD) from Fanger's PMV-PPD model. The percentage of subjects stating that thermal condition was unacceptability was always lower than that from PMV-PPD model within the intervals $(-1 ;-3)$ and $(+1 ;+3)$. Particularly, less than $10 \%$ of subjects considered the thermal environments as unacceptable in the interval of $(-1 ;-2)$.

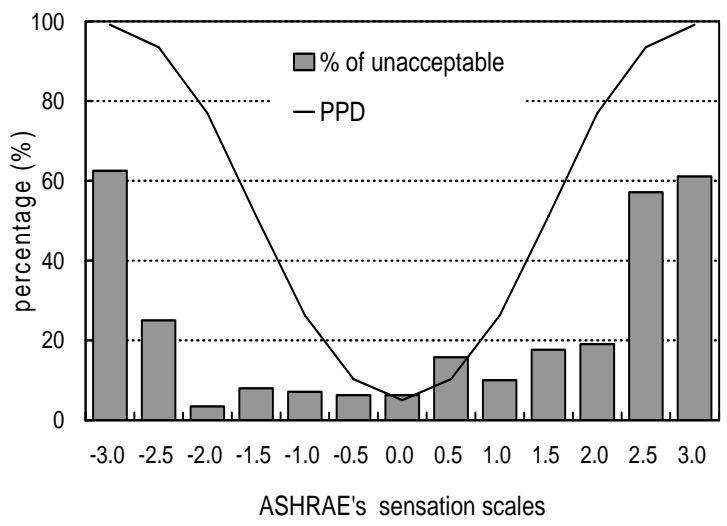

Fig. (3). Comparison of observed thermal acceptability between predicted percentages of dissatisfied from Fanger's model.

Fig. (4) shows the comparison of expectation (preference) responses with Fanger's PPD model. At warmer than neutral conditions, the PPD model underestimated the percentage of subjects voting "want to be cooler". Conversely, the PPD model matched well with the percentages of subjects voting "want to be warmer" in cooler than neutral conditions.

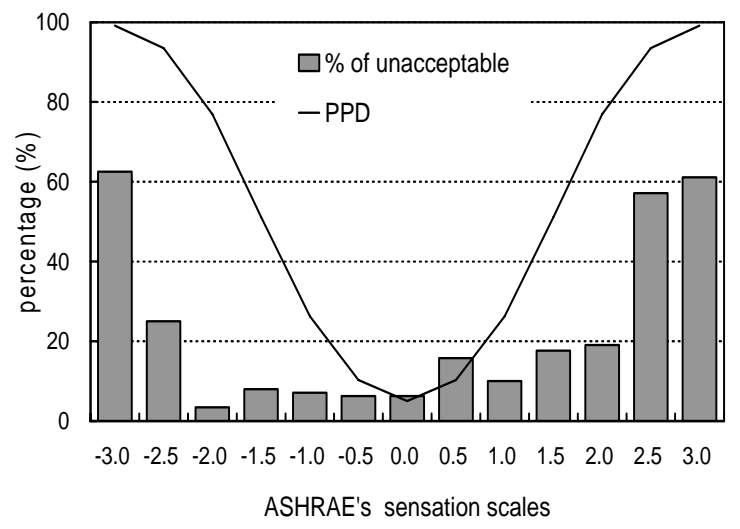

Fig. (4). Comparison of observed thermal preference between predicted percentages of dissatisfied from Fanger's model.

\section{Thermal Sensitivity and Neutral Temperature}

Thermal sensations are different among people, even though they are in the same environment. To reduce the in- dividual differences, de Dear [3] suggested that the bins' mean thermal sensation votes (MTSV), rather than the individual actual votes, be used in the analysis. Along with many other researchers, we have followed de Dear's suggestion.

The sensitivity of the subjects' thermal sensations to operative temperature was evaluated by examining MTSV responses for each half-degree interval. The data have been plotted in Fig. (5). The fitted regression lines for subjects' sensations versus operative temperature are:

$T S V=0.315 \times T_{0}-8.068, \quad R^{2}=0.805$

Again, the linear regression was applied to PMV model's prediction and operative temperature. A regression line for average binned predicted mean votes (PMV) was also superimposed in (Fig. 5). The regression equation fitted to PMV index values is:

$$
P M V=0.274 \times T_{0}-6.732, \quad R^{2}=0.985
$$

The coefficient of determinant $\left(R^{2}\right)$ between TSV/PMV and the operative temperature is 0.805 for Eq. (1) and 0.985 for Eq. (2). The values of $R^{2}$ indicate high significance between the observed /predicted thermal sensations and the indoor operative temperature.

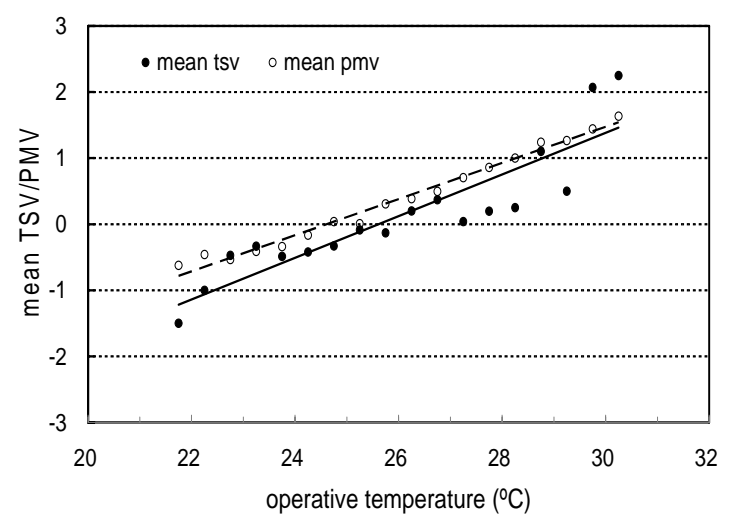

Fig. (5). Mean observed sensation compared to mean predicted sensation.

The slopes of the regression lines represent the sensitivity of the subjects with respect to the operative temperature. It is approximately $3.2^{\circ} \mathrm{C}$ per sensation unit for the observed gradient to $3.7^{\circ} \mathrm{C}$ per sensation unit for the PMV gradient. Clearly, the regression gradient on the PMV model underestimates the subjects' thermal sensitivity to operative temperature.

The neutrality condition is derived by solving Eqs. (1-2) for a mean thermal sensation vote of zero. Regression analysis of average binned TSV gave a neutral temperature of $25.6^{\circ} \mathrm{C}$, which is $1.0^{\circ} \mathrm{C}$ higher than that given by the average binned PMV model.

\section{Preferred Sensation and Temperature}

Probit analyses, employed for thermal sensation assessments by Ballantyne, Hill and Spencer [4], were conducted separately on requests for warmer and cooler conditions. The cumulate frequency distributions for "want to be warmer" and "want to be cooler" were plotted against the sensation of the thermal environment (Fig. (6)). Analysis of preference 
votes demonstrated an asymmetrical correlation between thermal sensation and thermal preference for all subjects. The point, located at the intersection of the two cumulate curves, corresponds to subject preference in terms of sensation. Such a preference did not coincide with the thermal neutral condition, but was shifted slightly toward a negative value on the sensation scale. The optimal sensation occurred at -0.8 . Moreover, about $60 \%$ of subjects who voted "neutrality" preferred to feel cool.

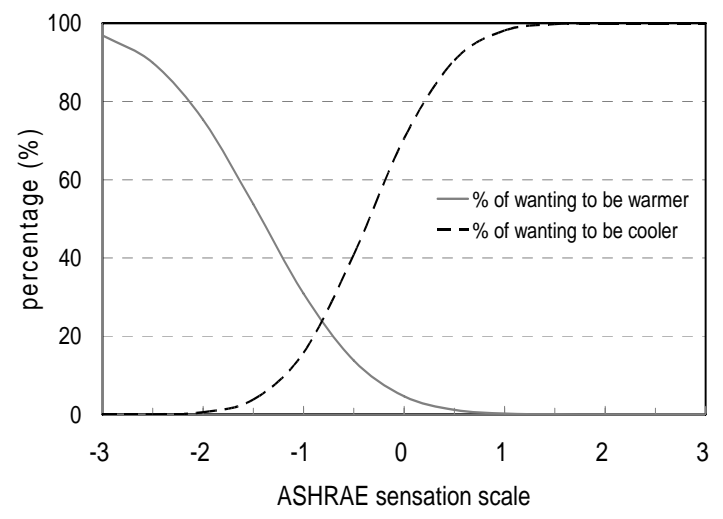

Fig. (6). Probit models for preferred thermal sensation.

Preferred temperature was assessed according to answers to thermal preference questions. Therefore, the percentages of subjects voted "wanting to be warmer" and "wanting to be cooler" was the object of probit analysis. Fig. (7) shows the probit analytical results. In Fig. (7), the right sigmoid curve corresponds to the group of "wanting to be cooler", and left curve is for the group of "wanting to be warmer". The "wanting to be cooler" curve and "wanting to be warmer" curve are not symmetrical. The gradient of observed percentage of "wanting to be warmer" against temperature is sharper than that of observed percentage of "wanting to be cooler", suggesting that subjects withstood a warm temperature better than cold temperatures.

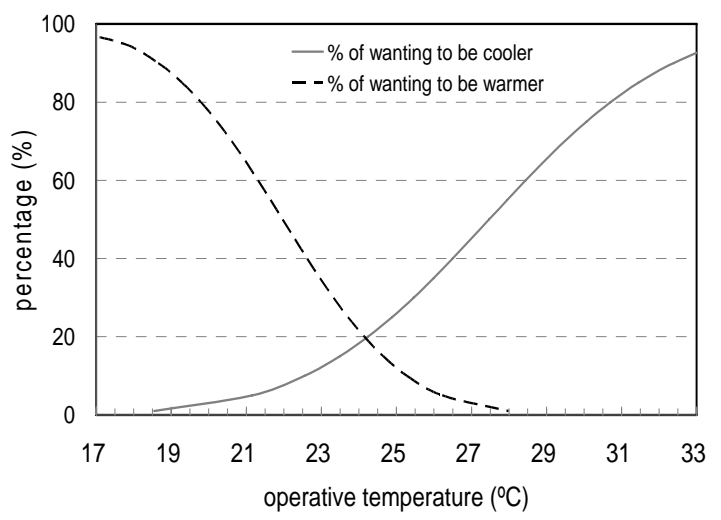

Fig. (7). Probit models for thermal preferred temperature.

The temperature where the two fitted lines intersect is the preferred temperature, because at this point an equal percentage of subjects preferred a warmer or cooler temperature. As estimated from the intersection of the curves, the preferred operative temperature was $24.1^{\circ} \mathrm{C}, 1.5^{\circ} \mathrm{C}$ lower than the ob- served neutral temperature, and $0.5^{\circ} \mathrm{C}$ lower than neutral temperature from binned PMV model. Many field studies obtained a similar finding, indicting that people in hot humid climates have a preferred temperature lower than neutral temperature, and, by inference, wish to live in a relatively cooler environment. We firmly believe that this inference explains the difference between neutral temperature and preferred temperature in this study.

\section{Thermal Comfortable Range}

One of major objectives of this study is to determine the range of thermal comfort. In ASHRAE standard 55, comfort zone is defined as a range of thermal environmental conditions of which $>80 \%$ of occupants express satisfaction. Therefore, the percentages of dissatisfaction resulting from votes beyond three central categories of ASHRAE scales in each temperature bin were plotted as a function of operative temperature in Fig. (8). The second degree polynomial regression curves were used to estimate the boundary of thermal acceptability, corresponding to the $80 \%$ thermal acceptability criterion of ASHRAE Standard 55. The margins of the acceptable zones obtained are $23.8-27.5^{\circ} \mathrm{C}$. When comparing to ASHRAE's comfort range, $23.0-27.0^{\circ} \mathrm{C}$, the comfortable range for subjects shifts to slightly warmer temperatures by about $0.5^{\circ} \mathrm{C}$.

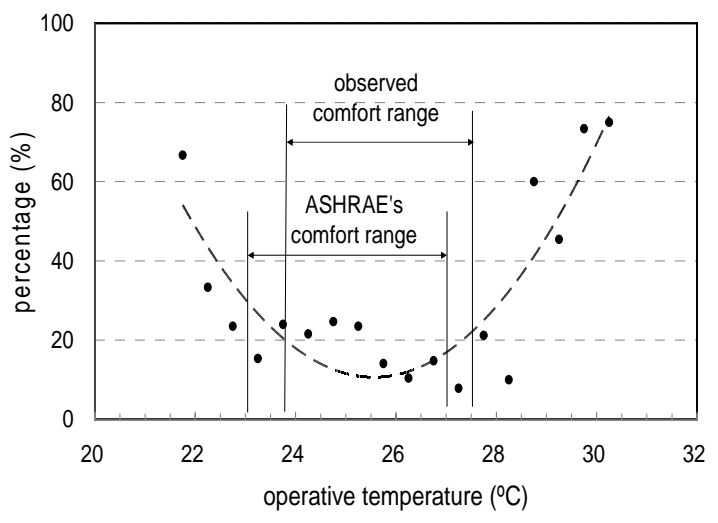

Fig. (8). Comparison of the observed comfort range with that recommended by ASHRAE standard 55.

This finding presents a completely different phenomenon from that indicated in Fig. (2). In Fig. (2), only 31\% of measured samples fell in the comfort zone, but $78 \%$ of subjects rated their thermal sensations as three central categories $(-1 ; 0 ;+1)$. Without taking care of humidity of indoor climate, it is noteworthy that the percentage of measured samples that fell into the ASHRAE comfortable temperature range (23.0$27.0^{\circ} \mathrm{C}$ ) is $70 \%$, which is little less than the level $(78 \%)$ of percentage of satisfied from thermal sensation votes. This indicates that subjects have perhaps acclimated to the climate of Taiwan, where the monthly average relative humidity is over $75 \%$ throughout the year, and have a leniency toward the humidity guideline in Standard 55. The same result was obtained in other studies $[5,6]$ by the authors.

\section{Comparisons with other Studies}

Many researches examined the comfort criteria of ASHRAE Standard 55 for their applicability in hot and humid climates in recent decades. Busch [7] carried out a field study in office buildings in Bangkok, Thailand.deDear et al. 
Table 3. A Summary of Neutral Temperature of Subjects Found in Hot-Humid Climates

\begin{tabular}{|c|c|c|}
\hline Researcher & Location & Neutral temperature \\
\hline \hline J. F. Busch & Bangkok, Thailand & $24.5^{\circ} \mathrm{C}$ \\
\hline R.J. De Dear, K.G. Leow et al. & Singapore & $24.2^{\circ} \mathrm{C}$ \\
\hline R.J. De Dear, M.E. Fountain & Townsville, Australia & $24.6^{\circ} \mathrm{C}$ \\
\hline T.H. Karyono & Jakarta, Indonesia & $26.7^{\circ} \mathrm{C}$ \\
\hline W.T. Chan et al. & HongKong & $23.5^{\circ} \mathrm{C}$ \\
\hline This study & Taiwan & $25.6^{\circ} \mathrm{C}$ \\
\hline
\end{tabular}

[8] conducted field experiments in both high rise residential buildings and office buildings in Singapore. In another study, De Dear and Fountain [9] undertook a field investigation on the indoor climates of office buildings in city of Townsville, Australia. Karyono [10] carried out a field study on thermal comfort and building energy in Jakarta, Indonesia. Chan et al. [11] finished a large-scale survey of thermal comfort in office premises in Hong Kong. A summary of neutral temperature of subjects found in above mentioned studies is shown in Table 3. The comparison indicated that occupants of Taiwan appear to be more tolerant than people in other countries, excluding Indonesia.

\section{CONCLUSION}

The field experiments were performed in 29 airconditioned offices over the country of Taiwan to investigate the comfort reception of workers in air-conditioned environments. The important conclusions of this study are as follows.

$69 \%$ of physical measurements in air conditioned offices fell outside the comfort zone of the ASHRAE Standard 55. Either by direct votes of acceptability or by indirect measures using central three categories of thermal sensation scales, more than third-four (88\% and $78 \%$ respectively) of subjects still satisfied with their thermal environments. The margins of the acceptable zones obtained from field survey are $23.8-27.5^{\circ} \mathrm{C}$. When comparing to ASHRAE's comfort range, the observed comfortable range shifts to slightly warmer temperatures by about $0.5^{\circ} \mathrm{C}$. However, without considering the indoor air humidity, the percentage of measured samples falling into the ASHRAE comfortable range is 70\% and slightly lower than the percentage of subjects voting central three categories of sensation scales. This indicates that occupants of Taiwan have perhaps acclimated to the humid climate and have a leniency toward the humidity guideline in Standard 55.

When comparing with the percentage of subjects stating that thermal condition was unacceptability, Fanger's PMVPPD model is always overemphasis. As comparing to results from thermal preference votes, the Fanger's model underestimated the percentage of subjects voting "want to be cooler" in warmer than neutral conditions, however, the PPD model matched well with the percentages of subjects voting "want to be warmer" in cooler than neutral conditions.

Probit analyses, conducted separately on requests for warmer and cooler conditions, found that the optimal sensa- tion occurred at -0.8 , which does not coincide with the thermal neutrality. The preferred operative temperature was $24.1^{\circ} \mathrm{C}$, which is also $1.5^{\circ} \mathrm{C}$ lower than the observed neutral temperature $\left(25.6^{\circ} \mathrm{C}\right)$.

When the neutral temperature was compared to those found in other countries with hot-humid climate, the observation depicts that occupants of Taiwan appear to be more tolerant.

\section{ACKNOWLEDGEMENT}

The authors would like to thank the National Science Council of Taiwan, for financially supporting this research under Contract No. NSC 95-2221-E-039-011. We express deep appreciations to those who fill the questionnaire.

\section{REFERENCES}

[1] ASHRAE, ANSI/ASHRAE Standard 55-1992, "Thermal environmental conditions for human occupancy". Atlanta: American Society of Heating, Refrigerating and Air-Conditioning Engineers, Inc., 2004.

[2] ISO, "ISO 7730-Moderate thermal environments-determination of the PMV and PPD indices and specification of the conditions for thermal comfort”, International Organization for Standardization, 1994.

[3] R.J. deDear, G.S. Brager, "Developing an adaptive model of thermal comfort and preference”, ASHRAE Transactions, vol. 104 (1), pp. $145-167,1998$

[4] E. R. Ballantyne, R. K. Hill and J. W. Spencer, "Probit analysis of thermal sensation assessments", International Journal of Biometeorology, vol. 21 (1), pp. 29-43, 1997.

[5] R.L. Hwang, T.P. Lin, M.J. Cheng and Jui-Hung Chien, "Patient thermal comfort requirement for hospital environments in Taiwan", Building and Environment 42 (2007) 2980-2987

[6] R.L. Hwang, T.P. Lin, N.J. Kuo. "Field experiments on thermal comfort in campus classrooms in Taiwan", Building and Energy, vol. 38, pp. 53-62, 2006.

[7] J.F. Busch, "Thermal responses to the Thai office environment", ASHRAE Transactions vol.96 (1), pp.859-872, 1990.

[8] R.J. deDear, K.G. Leow, S.C. Foo, "Thermal comfort in the humid tropics: field experiments in air-conditioned and naturally ventilated buildings in Singapore”, International Journal of Biometeorology, vol. 34, pp.259-265, 1991.

[9] R.J. deDear, M.E. Fountain, "Field experiments on occupant comfort and office thermal environments in a hot-humid climate", ASHRAE Transactions, vol. 100 (2), pp. 457-475, 1994.

[10] T.H. Karyono, "Report on thermal comfort and building energy studies in Jakarta-Indonesia”, Building and Environment, vol. 35, pp. 77-90, 1998.

[11] W.T. Chan, J. Burnett, R.J. de Dear, C.H. Ng, “A large-scale survey of thermal comfort in office premises in Hong Kong”, $A S H$ RAE Transactions, vol. 104 (1B), pp. 1172-1180, 1998. 